\title{
Left Atrial Mechanical Function Predicts Postoperative AF in Patients with Rheumatic Mitral Valve Disease Who Underwent Mitral Valve Surgery
}

\author{
Yan Jin, MD*, ${ }^{*}$ Yang Wang, ${ }^{1,2}$ Jian Zhang, MD*, ${ }^{1}$ Fengjie Yue, MM, ${ }^{1}$ Zongtao Yin, MD, ${ }^{1}$ Yan Zhu, MD, ${ }^{1}$ \\ Yan Yu, MD, ${ }^{1}$ Huishan Wang, $\mathrm{MD}, \mathrm{PhD}^{1}$ \\ ${ }^{1}$ Department of Cardiovascular Surgery, General Hospital of Northern Theater Command, Liaoning, China; ${ }^{2}$ Liaoning University of \\ Traditional Chinese Medicine, Liaoning, China
}

\section{ABSTRACT}

Objective: Postoperative atrial fibrillation $(\mathrm{PoAF})$ is a common complication after surgical mitral valve replacement. Late PoAF is independently associated with long-term mortality. This study aimed to test the utility of preoperative left atrial mechanical function as a predictor of early and late PoAF in clinical practice.

Methods: Patients $(\mathrm{N}=150)$ with a rheumatic mitral valve who underwent mitral valve replacement with or without tricuspid valvuloplasty and who were in stable sinus rhythm were included. Baseline characteristics and transthoracic echocardiographic assessment information on the day before surgery were collected. Em, Em', and Ei' indicate early diastolic peak velocity of the mitral valve, early diastolic velocity at the lateral wall of the mitral annulus, and early diastolic velocity at the interventricular septal annulus, respectively.

Results: Early PoAF was present in 59 of 150 patients (39.3\%), and 32 of 150 patients (21.3\%) developed late PoAF within 1 year after surgery. Among all of the variables examined, age, diabetes, early mitral filling velocity (Mitral E), left atrial mechanical function (Mitral A), Em/Em', Em/Ei', and mitral transvalvular gradient showed a significant correlation with PoAF. Only age, Mitral A, and mitral transvalvular gradient showed strong, significant correlations with the occurrence of late PoAF. In a multivariate analysis, predictors of late PoAF recurrence included early PoAF and Mitral A.

Conclusion: Routine evaluation of Mitral A is feasible and useful to predict early and late PoAF in patients with a rheumatic mitral valve undergoing surgical mitral valve replacement.

Received September 20, 2020; received in revised form October 22, 2020; accepted October 22, 2020.

*Y. Jin, Y. Wang, and J. Zhang contributed equally to this work.

Correspondence: Huishan Wang, Department of Cardiovascular Surgery, General Hospital of Northern Theater Command, No. 83, Wenhua Road, Shenbe District, Shenyang, Liaoning, 110016 China; 862428897382; fax: 862423912376 (e-mail: buishanw@126.com).
INTRODUCTION

Atrial fibrillation (AF) is a common complication after cardiac surgery and is associated with significantly increased morbidity, mortality, and total treatment costs [El-Chami 2010]. Reported incidences of early postoperative $\mathrm{AF}(\mathrm{PoAF})$ range from 10\% to 65\% [Mathew 2004; Zhang 2017; Zhang 2018]. Furthermore, early PoAF is known to increase the risk of late PoAF [Lanters 2018; Lee 2014], which has a high mortality rate [Park-Hansen 2018; Kawamoto 2018; Magruder 2016]. Patients who undergo surgical mitral valve replacement (MVR) for rheumatic mitral disease are at risk for developing PoAF, even after valve replacement [Park-Hansen 2018]. It is well documented that enlargement of the left atrium is associated with $\mathrm{AF}$ and its recurrence in patients with rheumatic mitral disease [Zhang 2017; Wang 2019; Wang 2018; Xu 2017]. However, the relationship between left atrial mechanical function and late PoAF is seldom investigated in patients undergoing mitral valve surgery. Left atrial mechanical function can be estimated by noninvasive techniques, including pulse wave Doppler across the mitral valve, during diastole in patients in sinus rhythm, with the transmitral A wave (Mitral A) corresponding to late diastolic filling of the left ventricle, associated with atrial contraction [Mottram 2005]. Therefore, the aim of this study was to explore the utility of evaluating left atrial mechanical function before surgery in predicting the risk of early and late PoAF among patients undergoing surgical MVR.

\section{Methods}

Eligibility Criteria

From January 2012 to December 2016, we retrospectively enrolled consecutive patients with a severe isolated rheumatic mitral valve who underwent MVR with or without tricuspid valvuloplasty at the Department of Cardiovascular Surgery, General Hospital of Northern Theater Command, Liaoning, China. The patients were evaluated the day before surgery and had to be in stable sinus rhythm as documented by 12-lead electrocardiography (ECG) and Holter. Patients were excluded from the study if they had (1) emergent surgery; (2) other, more than moderate aortic valvular disease or a valvular prosthesis; (3) a history of cardiac surgery; (4) a history of congenital cardiac abnormalities or cardiac tumors; (5) 
significant coronary artery disease; or (6) a history of arrhythmia, including atrial fibrillation (AF) and ventricular tachycardia. Finally, 150 patients met the criteria. Ethics approval was obtained from the Ethics Committee of the General Hospital of Northern Theater Command. Our research is in compliance with the Declaration of Helsinki.

\section{Surgical Procedure}

The surgical mitral valve replacement procedure was performed as described previously [Wang 2018; Jin 2013]. Briefly, all operations were performed by the same cardiac anesthesiologist, perfusionist, and surgical team. Under standard cardiopulmonary bypass with mild hypothermia $\left(34^{\circ} \mathrm{C}\right)$, mitral valve replacement was performed using an atrial septal approach. Antegrade cold potassium (16 mmol/L) cardioplegia was applied for regular repeated perfusion. Mitral valve replacement used mitral anterior leaflet resection and posterior leaflet preservation. Tricuspid valvoplasty was performed according to the pathological changes of the tricuspid valve. After cardiopulmonary bypass, transesophageal echocardiography was used to monitor the mean mitral transvalvular pressure difference $(3-8 \mathrm{mmHg})$.

\section{Early Postoperative AF}

The early PoAF monitoring was as described previously [Zhang 2017; Zhang 2018; Xu 2017]. Briefly, postoperative cardiac rhythms were continuously recorded during the first 4 to 5 days. Telemetry recordings, ECGs, and patient records were all manually evaluated for the presence of AF episodes. Early PoAF was defined as irregular RR intervals in the absence of distinct $\mathrm{P}$ waves, with a duration of $\geq 1$ minute, or for any length of time requiring an intervention for hemodynamic compromise, occurring within 14 days after the surgery.

\section{Late Postoperative AF}

AF that occurred or lasted beyond the first 12 months after surgery was considered late PoAF. Late PoAF was detected on either ECGs or 24-hour Holter recordings. If applicable, additional rhythm registrations obtained during the followup period were requested from the referring hospital [Lanters 2018].

\section{Echocardiography}

All patients underwent a 2-dimensional Doppler echocardiogram using PHILIPS IE33 (Andover, MA) 5-1 MHz probes. The early and late diastolic peak velocities of the mitral valve (Em and Am, respectively) and tricuspid valve (Et and At) was collected by pulse-wave tissue Doppler imaging (PW-TDI). Measurements of the mean mitral transvalvular pressure difference were used with the PW-TDI. Twodimensional area trace or Pt1/2 of the early-diastolic blood flow of the mitral valves was used to measure the mitral valve area (MVA). PW-TDI was used to measure the early diastolic, late diastolic, and systolic peak velocities at the lateral wall of the mitral annulus (Em', Am, and Sm'), the interventricular septal annulus ( $\mathrm{Ei}^{\prime}, \mathrm{Ai}^{\prime}$, and $\left.\mathrm{Si}^{\prime}\right)$, and the lateral wall of the tricuspid annulus (Et', At', and $\mathrm{St}^{\prime}$ ), and then Em/Em', $\mathrm{Em} / \mathrm{Ei}^{\prime}$, and $\mathrm{Et} / \mathrm{Et}^{\prime}$ were calculated. The extent of stenosis and regurgitation at the mitral, aortic, and tricuspid valves were judged by pulsed, continuous, and color Doppler echocardiography [Joint Task Force 2012; Nishimura 2014] and classified as slight (grade 1), mild (grade 2), moderate (grade

Table 1. Analysis of Echocardiographic Data of Early PoAF Patients*

\begin{tabular}{|c|c|c|c|}
\hline Variable & Early PoAF & & $P$ Value \\
\hline & No $(n=91)$ & Yes $(n=59)$ & \\
\hline $\mathrm{LAD}(\mathrm{mm})$ & $46.5 \pm 5.8$ & $46.2 \pm 5.8$ & .731 \\
\hline LVEDD (mm) & $43.6 \pm 5.3$ & $45.2 \pm 5.3$ & .084 \\
\hline RVOTd (mm) & $25.1 \pm 5.2$ & $25.5 \pm 4.3$ & .635 \\
\hline PAD (mm) & $23.7 \pm 4.5$ & $23.6 \pm 5.0$ & .934 \\
\hline LVEF (\%) & $58.5 \pm 2.8$ & $58.2 \pm 3.8$ & .558 \\
\hline $\operatorname{Em}(\mathrm{m} / \mathrm{s})$ & $2.02 \pm 0.68$ & $1.80 \pm 0.58$ & .043 \\
\hline $\operatorname{Am}(\mathrm{m} / \mathrm{s})$ & $1.94 \pm 0.63$ & $1.72 \pm 0.48$ & .023 \\
\hline $\mathrm{Et}(\mathrm{m} / \mathrm{s})$ & $0.47 \pm 0.13$ & $0.47 \pm 0.13$ & .871 \\
\hline At $(m / s)$ & $0.44 \pm 0.14$ & $0.43 \pm 0.14$ & .565 \\
\hline $\mathrm{Em}^{\prime}(\mathrm{cm} / \mathrm{s})$ & $5.06 \pm 1.76$ & $5.37 \pm 1.78$ & .299 \\
\hline $\mathrm{Am}^{\prime}(\mathrm{cm} / \mathrm{s})$ & $7.80 \pm 2.97$ & $7.29 \pm 2.69$ & .299 \\
\hline $\mathrm{Sm}^{\prime}(\mathrm{cm} / \mathrm{s})$ & $7.35 \pm 2.01$ & $7.41 \pm 1.55$ & .855 \\
\hline $\mathrm{Et}^{\prime}(\mathrm{cm} / \mathrm{s})$ & $8.89 \pm 2.87$ & $9.21 \pm 3.16$ & .527 \\
\hline $\mathrm{At}^{\prime}(\mathrm{cm} / \mathrm{s})$ & $14.08 \pm 4.34$ & $14.48 \pm 4.05$ & .566 \\
\hline $\mathrm{St}^{\prime}(\mathrm{cm} / \mathrm{s})$ & $12.39 \pm 2.70$ & $12.38 \pm 2.68$ & .976 \\
\hline $\mathrm{Em} / \mathrm{Em}^{\prime}$ & $45.7 \pm 24.1$ & $36.9 \pm 18.9$ & .016 \\
\hline $\mathrm{Ei}^{\prime}(\mathrm{cm} / \mathrm{s})$ & $4.38 \pm 1.76$ & $4.53 \pm 1.42$ & .603 \\
\hline $\mathrm{Ai}^{\prime}(\mathrm{cm} / \mathrm{s})$ & $6.54 \pm 1.81$ & $7.03 \pm 2.30$ & .155 \\
\hline $\mathrm{Si}^{\prime}(\mathrm{cm} / \mathrm{s})$ & $6.67 \pm 1.47$ & $6.84 \pm 1.54$ & .509 \\
\hline $\mathrm{Em} / \mathrm{Ei}^{\prime}$ & $50.1 \pm 27.8$ & $43.5 \pm 20.1$ & .024 \\
\hline $\mathrm{Et} / \mathrm{Et}^{\prime}$ & $10.07 \pm 3.63$ & $9.65 \pm 4.42$ & .527 \\
\hline PASP $\left(\mathrm{mmHg}^{\prime}\right.$ & $50.5 \pm 18.7$ & $47.6 \pm 18.5$ & .363 \\
\hline $\begin{array}{l}\text { Mitral transvalvular gradient } \\
(\mathrm{mmHg})\end{array}$ & $11.5 \pm 8.3$ & $8.6 \pm 5.3$ & .019 \\
\hline $\operatorname{MVA}\left(\mathrm{m}^{2}\right)$ & $1.12 \pm 0.44$ & $1.04 \pm 0.34$ & .768 \\
\hline MR grade & $2.29 \pm 0.91$ & $2.32 \pm 0.97$ & .865 \\
\hline TR grade & $2.16 \pm 0.53$ & $2.13 \pm 0.51$ & .702 \\
\hline
\end{tabular}

*Data are mean \pm standard deviation.

Em, Am, Et, and At indicate peak early and late inflow peak velocity of the transmitral and transtricuspid valves, respectively; $\mathrm{Em}^{\prime}, \mathrm{Ei}^{\prime}, \mathrm{Et}^{\prime}, \mathrm{Am}^{\prime}, \mathrm{Ai}^{\prime}$, $\mathrm{At}^{\prime}, \mathrm{Sm}^{\prime}, \mathrm{Si}^{\prime}$, and $\mathrm{St}^{\prime}$ indicate early and late diastolic and systolic peak velocities at the lateral mitral valve, interventricular septum, and lateral tricuspid of the annulus, respectively; LAD, left atrial diameter; LVEDD, left ventricular end-diastolic internal diameter; LVEF, left ventricular ejection fraction; MR, mitral regurgitation; MVA, mitral valve area; PAD, peripheral arterial disease; PASP, pulmonary artery systolic pressure; RVOTd, right ventricular outflow tract end diastolic diameter; TR, tricuspid regurgitation. 
3 ), or severe (grade 4). An MVA $<1.5 \mathrm{~cm}^{2}$ was diagnosed as severe mitral stenosis. Based on the tricuspid regurgitation spectrum, right ventricular systolic pressure (RVSP) was calculated with the following equation: $\mathrm{RVSP}=4 V 2+\Delta P$, where $V$ is the tricuspid regurgitation peak velocity and $\Delta P$ is the right atrial pressure $(10 \mathrm{mmHg})$. If the pulmonary valve has no stenosis, RVSP can be considered to be the pulmonary artery systolic pressure (PASP).

\section{Statistical Analysis}

All statistical calculations were carried out using SPSS 18.0 software (IBM, Chicago, IL). Differences in the distribution of host characteristics between cases and controls were evaluated by Pearson's $\chi^{2}$ test for categorical variables. To compare the characteristics of the 2 patient groups, independent Student's $t$ test and Mann-Whitney $U$ test were used. $\chi^{2}$ test was applied to compare sex and atrial fibrillation presence. Independent risk factors of PoAF were identified using multiple logistic regression analysis from the variables of $P<.1 . P<.05$ was considered significant in all comparisons.

\section{Results}

\section{Study Population}

A total of 150 patients (age $54.7 \pm 9.2$ years, 27 male [18\%]) with no history of preoperative atrial fibrillation met the study inclusion criteria and underwent mitral valve replacement between January 2012 and December 2016. Their baseline characteristics are summarized in Table 4. Early PoAF occurred in 59 patients (39.3\%). The patients with early PoAF were significantly older than the patients without early PoAF $(P=.001)$ (Table 4). Additionally, patients with diabetes mellitus were more likely to have early $\operatorname{PoAF}(P=.037)$ (Table 4).

There were no patients lost to follow-up and deaths within the 1-year period. Thirty-two patients $(21.3 \%)$ developed late PoAF during follow-up. Age was strongly associated with the occurrence of late PoAF $(P=.009)($ Table 5).

\section{Echocardiographic Parameters and PoAF}

Table 1 shows all of the preoperative echocardiographic parameters. Among the analyzed variables, early mitral filling

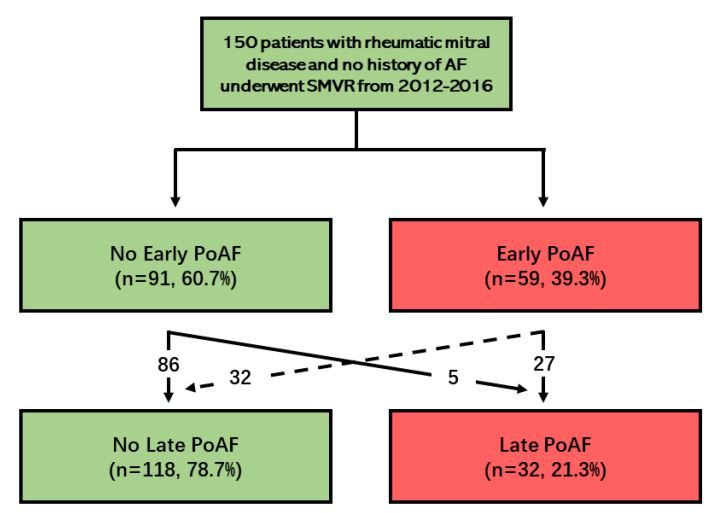

Figure 1. Rhythm outcomes for patients undergoing mitral valve replacement. SMVR indicates surgical mitral valve replacement. velocity (Mitral E), Mitral A, and mean mitral transvalvular pressure were significantly associated with early PoAF (Table 1). There was no significant difference between the measures of mitral valve area, pulmonary artery systolic pressure, or

Table 2. Analysis of Echocardiographic Data of Late PoAF Patients*

\begin{tabular}{|c|c|c|c|}
\hline Variable & Late PoAF & & $P$ Value \\
\hline & No (118) & Yes (32) & \\
\hline LAD (mm) & $46.2 \pm 5.9$ & $47.0 \pm 5.3$ & .515 \\
\hline LVEDD (mm) & $43.9 \pm 5.3$ & $45.5 \pm 5.1$ & .141 \\
\hline RVOTd (mm) & $25.0 \pm 4.7$ & $26.3 \pm 5.3$ & .194 \\
\hline PAD (mm) & $23.4 \pm 4.6$ & $24.3 \pm 4.9$ & .374 \\
\hline LVEF (\%) & $58.3 \pm 2.9$ & $58.7 \pm 4.4$ & .511 \\
\hline $\operatorname{Em}(\mathrm{m} / \mathrm{s})$ & $2.02 \pm 0.68$ & $1.74 \pm 0.62$ & .060 \\
\hline $\operatorname{Am}(\mathrm{m} / \mathrm{s})$ & $1.94 \pm 0.59$ & $1.57 \pm 0.41$ & .001 \\
\hline$E t^{\prime}(m / s)$ & $0.47 \pm 0.13$ & $0.47 \pm 0.13$ & .422 \\
\hline At $(m / s)$ & $0.44 \pm 0.14$ & $0.43 \pm 0.14$ & .500 \\
\hline $\mathrm{Em}^{\prime}(\mathrm{cm} / \mathrm{s})$ & $5.11 \pm 1.73$ & $5.45 \pm 1.87$ & .330 \\
\hline $\mathrm{Am}^{\prime}(\mathrm{cm} / \mathrm{s})$ & $7.74 \pm 3.03$ & $7.06 \pm 2.08$ & .243 \\
\hline $\mathrm{Sm}^{\prime}(\mathrm{cm} / \mathrm{s})$ & $7.31 \pm 1.85$ & $7.58 \pm 1.78$ & .475 \\
\hline $\mathrm{Et}^{\prime}(\mathrm{cm} / \mathrm{s})$ & $9.15 \pm 3.03$ & $8.52 \pm 2.78$ & .297 \\
\hline$A t^{\prime}(\mathrm{cm} / \mathrm{s})$ & $14.35 \pm 4.30$ & $13.81 \pm 3.55$ & .517 \\
\hline $\mathrm{St}^{\prime}(\mathrm{cm} / \mathrm{s})$ & $12.36 \pm 2.74$ & $12.48 \pm 2.52$ & .823 \\
\hline $\mathrm{Em} / \mathrm{Em}^{\prime}$ & $44.0 \pm 22.4$ & $35.6 \pm 17.2$ & .055 \\
\hline $\mathrm{Ei}^{\prime}(\mathrm{cm} / \mathrm{s})$ & $4.53 \pm 1.74$ & $4.08 \pm 1.11$ & .170 \\
\hline $\mathrm{Ai}^{\prime}(\mathrm{cm} / \mathrm{s})$ & $6.72 \pm 2.04$ & $6.79 \pm 1.98$ & .856 \\
\hline $\mathrm{Si}^{\prime}(\mathrm{cm} / \mathrm{s})$ & $6.74 \pm 1.54$ & $6.74 \pm 1.34$ & .985 \\
\hline $\mathrm{Em} / \mathrm{Ei}^{\prime}$ & $50.1 \pm 26.0$ & $46.4 \pm 23.2$ & .487 \\
\hline $\mathrm{Et} / \mathrm{Et}^{\prime}$ & $10.16 \pm 4.05$ & $8.94 \pm 3.44$ & .126 \\
\hline PASP $(\mathrm{mmHg})$ & $49.7 \pm 18.2$ & $48.3 \pm 20.3$ & .725 \\
\hline $\begin{array}{l}\text { Mitral transvalvular gradient } \\
(\mathrm{mmHg})\end{array}$ & $11.0 \pm 7.64$ & $7.97 \pm 5.84$ & .042 \\
\hline $\operatorname{MVA}\left(\mathrm{m}^{2}\right)$ & $1.03 \pm 0.39$ & $1.02 \pm 0.44$ & .863 \\
\hline MR grade & $2.25 \pm 0.87$ & $2.52 \pm 1.12$ & .150 \\
\hline TR grade & $2.13 \pm 0.49$ & $2.24 \pm 0.62$ & .266 \\
\hline
\end{tabular}

*Data are mean \pm standard deviation.

$\mathrm{Em}, \mathrm{Am}, \mathrm{Et}$, and At indicate peak early and late inflow peak velocity of the transmitral and transtricuspid valves, respectively; $\mathrm{Em}^{\prime}, \mathrm{Ei}^{\prime}, \mathrm{Et}^{\prime}, \mathrm{Am}^{\prime}, \mathrm{Ai}^{\prime}$, $\mathrm{At}^{\prime}, \mathrm{Sm}^{\prime}, \mathrm{Si}^{\prime}$, and $\mathrm{St}^{\prime}$ indicate early and late diastolic and systolic peak velocities at the lateral mitral valve, interventricular septum, and lateral tricuspid of the annulus, respectively; LAD, left atrial diameter; LVEDD, left ventricular end-diastolic internal diameter; LVEF, left ventricular ejection fraction; MR, mitral regurgitation; MVA, mitral valve area; $P A D$, peripheral arterial disease; PASP, pulmonary artery systolic pressure; RVOTd, right ventricular outflow tract end diastolic diameter; TR, tricuspid regurgitation. 
left atrial diameter in our cohort (Table 1). Interestingly, there was a significant reduction in Mitral A wave and mitral transvalvular pressure among patients who developed late PoAF (Table 2).

\section{Relationship between Early PoAF and Late PoAF}

Rhythm outcomes are shown in Figure 1. Twenty-seven of 59 patients (45.7\%) with early PoAF developed late PoAF after mitral valve replacement (Figure 1). Consequently, there was a strong correlation between early PoAF and late PoAF $(P<.001)$ (Table 6$)$.

\section{Prediction of Late PoAF}

Univariate and multivariate logistic regression analyses for the prediction of late PoAF are summarized in Table 3. Multivariate logistic analysis showed that Mitral A and early

Table 3. Univariable and multivariable logistic regression analysis of risk factors of late PoAF

\begin{tabular}{|c|c|c|c|c|c|c|}
\hline \multirow[t]{2}{*}{ Factor } & \multicolumn{3}{|c|}{ Univariable Logistic Regression } & \multicolumn{3}{|c|}{ Multivariable Logistic Regression } \\
\hline & OR & $95 \% \mathrm{Cl}$ & $P$ value & OR & $95 \% \mathrm{Cl}$ & $P$ Value \\
\hline $\mathrm{Em}$ & 2.017 & 1.007 to 4.039 & .048 & 1.561 & 0.225 to 10.85 & .652 \\
\hline $\mathrm{Am}$ & 4.069 & 1.693 to 9.777 & .002 & 20.128 & 2.811 to 144.12 & .003 \\
\hline Mitral transvalvular gradient & 1.088 & 1.006 to 1.176 & .034 & 0.805 & 0.631 to 1.027 & .081 \\
\hline Early PoAF & 14.51 & 5.145 to 40.93 & $<.001$ & 15.607 & 4.925 to 49.46 & $<.001$ \\
\hline
\end{tabular}

OR indicates odds ratio; $\mathrm{Cl}$, confidence interval.

Table 4. Demographic and Clinical Characteristics by Presence of Early PoAF*

\begin{tabular}{lccc}
\hline Characteristic & Early PoAF & & $P$ Value \\
\hline & No $(\mathrm{n}=91)$ & Yes $(\mathrm{n}=59)$ & \\
Age $(\mathrm{y})$ & $52.73 \pm 9.66$ & $57.93 \pm 7.67$ & .001 \\
Male sex & $17(18.6)$ & $10(16.9)$ & .787 \\
BSA (m $\left.{ }^{2}\right)$ & $1.73 \pm 0.16$ & $1.75 \pm 0.15$ & .523 \\
BMl $\left(\mathrm{kg} / \mathrm{m}^{2}\right)$ & $22.75 \pm 2.70$ & $22.69 \pm 2.91$ & .925 \\
Hypertension & $19(20.8)$ & $10(16.9)$ & .551 \\
Diabetes mellitus & $2(2.2)$ & $7(11.8)$ & .037 \\
Heart rate (bpm) & $78.96 \pm 11.34$ & $78.82 \pm 14.60$ & .954 \\
Smoking & $20(21.9)$ & $12(20.3)$ & .811 \\
Blood glucose (mmol/L) & $5.42 \pm 1.71$ & $5.31 \pm 1.09$ & .722 \\
Albumin (mg/dL) & $40.65 \pm 5.99$ & $39.82 \pm 5.82$ & .438 \\
Creatinine ( $\mu$ mol/L) & $63.57 \pm 20.04$ & $64.19 \pm 18.32$ & .857 \\
Cardiopulmonary bypass & $99.3 \pm 36.7$ & $104.9 \pm 59.1$ & .594 \\
time (min) & & & \\
Aortic clamp time (min) & $62.2 \pm 34.5$ & $58.68 \pm 27.1$ & .602 \\
Blood product transfusion & $47(51.6)$ & $35(59.3)$ & 0.546 \\
Combined TVP & $21(23.0)$ & $14(23.7)$ & 0.927 \\
\hline & & & \\
\hline
\end{tabular}

*Data are mean \pm standard deviation or $\mathrm{n}(\%)$.

BMI indicates body mass index; BSA, body surface area; TVP, tricuspid valvuloplasty.
Table 5. Demographic and Clinical Characteristics by Presence of Late PoAF*

\begin{tabular}{lccc}
\hline Characteristic & Late PoAF & & P Value \\
\hline & No $(\mathrm{n}=118)$ & Yes $(\mathrm{n}=32)$ & \\
Age $(\mathrm{y})$ & $53.76 \pm 9.41$ & $58.53 \pm 7.72$ & .009 \\
Male sex & $28(23.7)$ & $4(12.5)$ & .361 \\
BSA (m $\left.{ }^{2}\right)$ & $1.75 \pm 0.17$ & $1.72 \pm 0.12$ & .418 \\
BMl (kg/m $\left.{ }^{2}\right)$ & $22.68 \pm 2.90$ & $22.84 \pm 2.48$ & .807 \\
Hypertension & $23(19.5)$ & $6(18.7)$ & .925 \\
Diabetes mellitus & $7(5.93)$ & $2(6.25)$ & .724 \\
Heart rate (bpm) & $78.71 \pm 11.69$ & $79.50 \pm 15.23$ & .768 \\
Smoking & $26(22.0)$ & $6(18.7)$ & .291 \\
Blood glucose (mmol/L) & $5.32 \pm 1.48$ & $5.56 \pm 1.53$ & .468 \\
Albumin (mg/dL) & $40.45 \pm 6.01$ & $39.89 \pm 5.65$ & .652 \\
Creatinine ( $\mu$ mol/L) & $63.90 \pm 20.72$ & $63.57 \pm 13.82$ & .936 \\
Cardiopulmonary bypass & $100 \pm 38.3$ & $103.3 \pm 64.9$ & .826 \\
time (min) & & & \\
Aortic clamp time (min) & $60.6 \pm 28.3$ & $58.04 \pm 34.9$ & .735 \\
Blood product transfusion & $63(53.8)$ & $19(59.3)$ & .356 \\
Combined TVP & $29(24.5)$ & $6(18.7)$ & .489 \\
\hline & & & \\
\hline
\end{tabular}

*Data are mean \pm standard deviation or $\mathrm{n}(\%)$.

BMI indicates body mass index; BSA, body surface area; TVP, tricuspid valvuloplasty. 
PoAF were significant and independent risk factors for late PoAF (Table 3).

\section{Discussion}

Among a group of patients with severe rheumatic mitral valve disease who underwent mitral valve replacement, we observed that early PoAF affected nearly $40 \%$ of the cohort. We also assessed the correlation between left atrial mechanical function (Mitral A) before surgery and late PoAF. Preoperative Mitral A and early PoAF after surgery are independent factors in the prediction of late PoAF. It has been reported that late PoAF is independently associated with long-term mortality [Kawamoto 8; Park 2017]. In accordance with previous findings, our data also suggest that early PoAF was the most powerful predictor of late mortality.

Meanwhile, the incidence of early PoAF in valve surgery is different from that of isolated coronary artery bypass grafting [Zhang 2017; Zhang 2018; Lanters 2018]. This may indicate that the mechanisms of PoAF are diverse. Factors promoting the development of early PoAF after cardiothoracic surgery include, for example, an inflammatory response, sympathetic activation, and oxidative stress [Lanters 2018]. In patients with rheumatic mitral valvular disease, the arrhythmogenic substrate is present and extensive. Owing to the mitral valve disease, atrial alterations at the structural, electrical, and contractile levels create higher vulnerability to the development of AF [Wijffels 1995]. Therefore, strategies for the prevention of PoAF should be precise.

In our study, multivariate analysis also found that a significant reduction in Mitral A was an independent characteristic of the late PoAF patients with sinus rhythm and rheumatic mitral valve disease; that is, those rheumatic mitral valve disease patients whose preoperative left atrial systolic function was significantly reduced were more prone to late AF after surgery. A greater left atrium size increases the surface area, leading to AF, as previously well documented by our group and others [Zhang 2017; Damiano 2011]. However, in our cohort, the left atrium size of patients with rheumatic mitral valve disease did not predict PoAF. One explanation is that the mean left atrium size was large $(>45 \mathrm{~mm})$ in our cohort, owing to the longstanding underlying rheumatic mitral valve disease, which likely influenced the data.

The assessment of left atrium function provides further insights into the consequences of left atrium structural remodeling [Delgado 2017]. The A peak is the left ventricular end diastolic blood flow through the atrioventricular valve, caused by atrial contractions. Clinical measurements of the $\mathrm{E}$ peak, A peak, and mitral annular tissue Doppler velocity can be used to evaluate changes in ventricular diastolic function [Nagueh 2009; Rudski 2010]. The A peak and the $\mathrm{P}$ wave on ECG are the mechanical and electrical activities of the left atrial contraction, respectively. The maximum velocity and time velocity integral of the A peak at the mitral valve are related to the contractile function of the left atrium. For patients with mitral valve disease, especially rheumatic mitral stenosis, the A peak at the mitral valve can reflect changes in left atrial function. The dynamic changes of these data can be used to quantitatively assess the changes in atrial function
Table 6. Relation between Early PoAF and Late PoAF*

\begin{tabular}{lccc}
\hline Early PoAF & Late PoAF & & $P$ Value \\
\hline & No $(\mathrm{n}=118)$ & Yes $(\mathrm{n}=32)$ & \\
No (91) & $86(72.9)$ & $5(15.6)$ & $<.001$ \\
Yes (59) & $32(27.1)$ & $27(84.4)$ & \\
\hline
\end{tabular}

*Data are $n(\%)$.

and ventricular diastolic function. When atrial fibrillation occurs, left atrial systolic function decreases, and the Mitral A wave disappears or is reduced [Akilli 2019]. In our data, the preoperative Mitral A wave decreased before the AF and predicted AF after surgery. In addition, measurements of the E peak, A peak, and mitral annular tissue Doppler velocity are characterized by good repeatability, easy operation, and easy data quantification, and they should be well applied in routine follow-up observations of patients.

\section{Limitations}

This was a single-center retrospective analysis of a small patient cohort. In addition, the relatively small sample size in this study limited the statistical capacity to detect interactions between left atrial mechanical function and other major risk factors. Further prospective studies are needed to confirm these findings with a larger sample size. The greatest limitation of this study is the absence of atrial strain measurements, which is an emerging modality for the assessment of left atrial function [Pathan 2018]. This has grounds for future study.

\section{Conclusion}

According to our study conducted on a population of patients with rheumatic mitral valve disease, increased Mitral A has an independent role in predicting early and late PoAF. Furthermore, preoperative left atrial function (Mitral A) could also enable us to more accurately detect patients who are at risk and thereby improve the effects of prophylactic treatments.

\section{ACKNOWLEDGMENTS}

This work was supported by grants from the National Natural Sciences Fund Project of China (81771833, 81970310) and National Scientific Research Foundation of Liaoning Province in China (20180550959, 2020-KF-12-01).

\section{REFERENCES}

Akilli H, Aribas A, Icli A, et al. Predictive value of transmitral A-wave acceleration time for paroxysmal atrial fibrillation. Echocardiography 2019;36:1633-1638.

Damiano RJ, Jr., Schwartz FH, Bailey MS, et al. The Cox maze IV procedure: Predictors of late recurrence. J Thorac Cardiovasc Surg 2011;141:113-121. 
Delgado V, Di Biase L, Leung M, et al. Structure and function of the left atrium and left atrial appendage: AF and stroke implications. J Am Coll Cardiol 2017;70:3157-3172.

El-Chami MF, Kilgo P, Thourani V, et al. New-onset atrial fibrillation predicts long-term mortality after coronary artery bypass graft. J Am Coll Cardiol 2010;55:1370-1376.

Jin Y, Wang HS, Wang ZW, et al. Risk factors for midterm cardiac function deterioration after valve replacement surgery in patients with rheumatic mitral stenosis. J Card Fail 2013;19:565-570.

Joint Task Force on the Management of Valvular Heart Disease of the European Society of Cardiology (ESC), European Association for Cardio-Thoracic Surgery (EACTS), Vahanian A, et al. Guidelines on the management of valvular heart disease (version 2012). Eur Heart J 2012;33:2451-2496.

Kawamoto N, Fujita T, Fukushima S, et al. Late onset of atrial fibrillation in patients undergoing mitral valve repair for type II dysfunction. J Cardiol 2018;71:346-351.

Lanters EAH, Teuwen CP, Yaksh A, et al. Intraoperative inducibility of atrial fibrillation does not predict early postoperative atrial fibrillation. J Am Heart Assoc 2018;7.

Lee SH, Kang DR, Uhm JS, et al. New-onset atrial fibrillation predicts long-term newly developed atrial fibrillation after coronary artery bypass graft. Am Heart J 2014;167:593-600.e1.

Magruder JT, Collica S, Belmustakov S, et al. Predictors of late-onset atrial fibrillation following isolated mitral valve repairs in patients with preserved ejection fraction. J Card Surg 2016;31:486-492.

Mathew JP, Fontes ML, Tudor IC, et al. A multicenter risk index for atrial fibrillation after cardiac surgery. JAMA 2004;291:1720-1729.

Mottram PM, Marwick TH. Assessment of diastolic function: What the general cardiologist needs to know. Heart 2005;91:681-695.

Nagueh SF, Appleton CP, Gillebert TC, et al. Recommendations for the evaluation of left ventricular diastolic function by echocardiography. J Am Soc Echocardiogr 2009;22:107-133.

Nishimura RA, Otto CM, Bonow RO, et al. 2014 AHA/ACC guideline for the management of patients with valvular heart disease: Executive summary: A report of the American College of Cardiology/American Heart Association Task Force on Practice Guidelines. J Am Coll Cardiol
2014;63:2438-2488

Park YM, Cha MS, Park CH, et al. Newly developed post-operative atrial fibrillation is associated with an increased risk of late recurrence of atrial fibrillation in patients who underwent open heart surgery: Longterm follow up. Cardiol J 2017;24:633-641.

Park-Hansen J, Greve AM, Clausen J, et al. New-onset of postoperative atrial fibrillation is likely to recur in the absence of other triggers. Ther Clin Risk Manag 2018;14:1641-1647.

Pathan F, Sivaraj E, Negishi K, et al. Use of atrial strain to predict atrial fibrillation after cerebral ischemia. JACC Cardiovasc Imaging 2018;11:1557-1565.

Rudski LG, Lai WW, Afilalo J, et al. Guidelines for the echocardiographic assessment of the right heart in adults: a report from the American Society of Echocardiography endorsed by the European Association of Echocardiography, a registered branch of the European Society of Cardiology, and the Canadian Society of Echocardiography. J Am Soc Echocardiogr 2010;23:685-713.

Wang H, Han J, Wang Z, et al. A prospective randomized trial of the cutand-sew Maze procedure in patients undergoing surgery for rheumatic mitral valve disease. J Thorac Cardiovasc Surg 2018;155:608-617.

Wang H, Han J, Wang Z, et al. Efficacy of cut-and-sew surgical ablation for atrial fibrillation in patients with giant left atria undergoing mitral valve surgery: A propensity-matched analysis. Semin Thorac Cardiovasc Surg 2019;31:796-802.

Wijffels MC, Kirchhof CJ, Dorland R, et al. Atrial fibrillation begets atrial fibrillation. A study in awake chronically instrumented goats. Circulation 1995;92:1954-1968.

Xu S, Zhang J, Xu YL, et al. Relationship between angiotensin converting enzyme, apelin, and new-onset atrial fibrillation after off-pump coronary artery bypass grafting. Biomed Res Int 2017;2017:7951793.

Zhang J, Xu S, Xu Y, et al. Relation of mitochondrial DNA copy number in peripheral blood to postoperative atrial fibrillation after isolated offpump coronary artery bypass grafting. Am J Cardiol 2017;119:473-477.

Zhang J, Xu Y, Xu S, Liu Y, Yu L, Li Z, Xue X, Wang H. Plasma circular RNAs, Hsa_circRNA_025016, predict postoperative atrial fibrillation after isolated off-pump coronary artery bypass grafting. J Am Heart Assoc 2018;7:e006642. 